\title{
É possível viver o digital na multimídia utilizada com fins educacionais?
}

\author{
Maria Cristina Villanova Biazus ${ }^{1}$
}

Resumo: este texto apresenta uma análise de alguns projetos educacionais em meio digital com foco educacional nos quais a imagem é o objeto principal de estudo, discutindo as principais características apresentadas nestes ambientes tecnológicos com vistas a um percurso educativo.

Palavras-chave: multimídia, interatividade, sites educacionais, educação digital, imagem digital.

Title: Is it possible to live the digital way of life in the multimedia used for educational purposes?

Abstract: this text presents an analyses of some educational projects in digital media with an educational focus in which the image is the main object of study. It discusses the main characteristics presented in these technological environments under the perspective of an educational trend.

Key-words: multimedia, interactivity, educational sites, digital education, digital image.

\section{Introdução}

Neste texto discutimos algumas práticas em multimídia para a educação, através da análise de alguns sites nos quais a imagem é o objeto de estudo, levando em consideração as possibilidades educacionais de cada um, o que poderia levar a pensar nas condições de excelência para propostas multimídia na educação. Fazemos um recorte e não estamos analisando, neste texto, o que se considera uma comunidade virtual de aprendizagem.

Considerando que: "A imagem é uma atividade que coloca em jogo técnicas $e$ um sujeito (operário, artesão ou artista, segundo cada cultura) operando com estas técnicas, mas possuidor de um saber-fazer que leva sempre o traço voluntário, ou não, de uma certa singularidade”, como nos diz Couchot (2003), buscamos analisar sob este enfoque da individualidade e autonomia do sujeito que cria / observa (recria, reconstrói, relê) a imagem, as propostas educacionais em meio digital.

O que se observa é que novas formas de comunicação estão trazendo mudanças a algumas verdades estabelecidas, embora ainda se encontre a utilização de um meio relativamente novo como a web sendo trabalhado de maneira tradicional, sem utilizar as particularidades e potencialidades das tecnologias digitais. $\mathrm{O}$ ciberespaço possibilita experiências e atividades pedagógicas inovadoras o que gera novos conceitos e modos de aprendizagem, como a ciberaprendizagem (Alava, 2002). Estes conceitos estão presentes nos materiais multimídia para uso educacional?

Viver o digital pressupõe interatividade e um expandir da moldura conceitual de linguagens para permitir novos pensares e viabilizar o acesso aos ambientes digitais flexíveis em que estarão sendo desenvolvidos processos educacionais. A flexibilidade

${ }^{1}$ Professora doutora - Instituto de Artes / Departamento de Artes Visuais / UFRGS. 
das trocas e interações que permite colaboração em projetos é uma característica que se revela produtiva em termos de utilização dos meios eletrônicos na educação.

No que se refere à imagem, a interatividade, condição essencial para que algumas imagens (obras de arte digital) aconteçam, tem um caráter de tempo real. " $A$ interatividade não espera...”, diz Couchot, “... pois o modo dialógico sobre o qual se estabelecem as relações entre o artista, as obras e os espectadores exige um imediatismo quase absoluto" (2003, p. 302). A interação parece, então, configurar-se como elemento fundamental de uma proposta de multimídia educacional.

Sobre a interação do sujeito/educando com a imagem digitalizada de obras de arte observamos em estudos anteriores (Biazus, 2001) que: "No caso específico da interação no meio digital dá-se um interessante acoplamento entre os sistemas cognitivos do sujeito e a obra do outro veiculada/gerada no e com o meio digital, bem como do sujeito com o próprio ambiente”. Os ganhos em termos de desenvolvimento de processos educacionais utilizando a imagem são evidentes e uma vez que o sujeito se constrói na ação mediante a interação com o meio/contexto, a interatividade torna-se condição básica neste processo.

Para identificar algumas das características favorecedoras e/ou constritoras no desenvolvimento de processos educacionais e que estão presentes no material multimídia centrado na utilização de imagens disponível hoje aos usuários, alguns sites foram selecionados para análise tendo por base a sua proposta de utilização das imagens digitais.

\section{Viajando por alguns sites e web pages que possuem enfoque educativo}

$\mathrm{O}$ site do MOWA, Museu de Web $\mathrm{Arte}^{2}$ é um museu virtual dedicado à arte, tecnologia e cultura da web. Consiste em um site no qual artistas que realizam obras utilizando os meios digitais mostram seu trabalho. As obras são apresentadas de modo interativo e as galerias mostram uma nova leitura em termos de curadoria, pois estão exibidas em categorias tais como: coisas que se movem (imagens virtuais que apresentam movimento que realmente mudam ao passar do tempo por estarem programas com um contador, ou imagens que mudar ao acionar o mouse) ou coisas para fazer (imagens virtuais do tipo button em que a interação do observador é necessária para que um som e a cor apareçam). Há uma galeria infantil com jogos interativos na qual a utilização de estímulos complementares textuais, gráficos, auditivos e visuais são utilizados com vistas a implementar os processos aprendizagem nos ambientes digitais (Sherry, 1997) citado por (Alava, 2002). Neste caso específico, estamos falamos em desenvolver a percepção da forma visual. Mesmo este não sendo um espaço aberto, como propõe Alava, por não remeter a outros locais em que este tipo de proposta seja também discutido, ele disponibiliza processos em que a interação com a obra é fundamental para que ela se mostre na sua total concepção, evidenciando modos que só a vivência em meio digital possibilita.

Embora esta interação não aconteça de modo sistemático, ela estabelece uma geração de novas possibilidades pelas relações que se criam via interação com o meio digital. O primeiro contato com a obra, neste caso - digital -, poderia vir a estabelecer uma relação dialógica, pois vemos em Bakhtin (2000) que: "ver uma coisa, tomar consciência dela pela primeira vez, significa estabelecer uma relação dialógica com a

\footnotetext{
${ }^{2}$ Disponível em http://www.mowa.org/ Acessado em 05/08/2003.
} 
coisa: ela não existe mais só em si e para si, mas para algum outro”. Desse modo, o meio digital em que este obra foi gerada e só através do qual poderá ser apreciada pelo observador, necessita ser viabilizado num processo educacional para que o sujeito possa viver o digital.

O site do MOMA ${ }^{3}$, Museu de Arte Moderna de New York disponibiliza o art safari como parte integrante de seu projeto educativo. Este projeto consta de 5 obras de arte do acervo do museu, nas quais a imagem de algum animal está presente. Seguindo um cuidadoso caminho para proporcionar ao usuário uma leitura destas obras, cujas imagens foram digitalizadas para estarem nesta galeria on-line, há uma maior participação do usuário, um público alvo que o próprio museu define como sendo crianças e suas famílias. O usuário deve responder a um bem ordenado conjunto de perguntas que solicitam descrever, analisar, imaginar, criar e recriar formas gráficas, com base em cada uma das 5 obras. Estas respostas em forma de texto e de desenhos são enviadas ao site para publicação (não instantânea, pois há uma mediação). Neste site encontramos elementos que "apontam, justamente para os processos que o educando pode realizar nos ambientes digitais, e que dele são específicos, ou seja, a possibilidade de recriar seu universo simbólico/estético, num processo dialógico de trocas, com a cultura do seu tempo, viabilizada pela virtualidade da interface" (Biazus, 2001).

Ao utilizar este site em sala de aula, com educandos que já conheciam algumas destas obras, constatamos que houve um despertar da percepção para detalhes não percebidos antes. A possibilidade interessante deste projeto on-line é que ele oferece ao observador a chance de recriar a história, de inventar um novo processo. É assim que entendemos o processo da criação como uma aproximação à vida pelo lado de fora, recriando a própria história, dentro da visão de Bakhtin. 'É assim que o artista e a arte em geral criam uma visão de mundo absolutamente nova, uma imagem do mundo, uma realidade da carne mortal do mundo que nenhuma outra atividade criadora poderia produzir" (Bakhtin, 2000, p. 205).

Dentro deste enfoque, uma proposta de multimídia que seja favorecedora de processos educativos e criativos deveria ser gerada dentro da concepção de que o sujeito possa ter a chance de exercer a sua autonomia ante a técnica, que, muitas vezes determina os processos. A interação do observador com o mundo digital solicitando a sua participação para que a imagem/obra se realize faz com que ele perceba e construa novas relações envolvendo imagem, sujeito e o meio que veicula e/ou gera esta imagem.

Outra proposta de educação on-line, a Eduweb ${ }^{4}$ disponibiliza projetos que podem ser utilizados em várias áreas de ensino com enfoque maior em arte, ciência e história. Os projetos disponibilizados no site que lidam especialmente com imagens buscam um desenvolvimento da percepção visual através de imagens de obras de arte.

Um dos projetos, desenvolvido em forma narrativa, é apresentado sob a forma de uma história cujo fio condutor é um detetive que ajuda uma moça a identificar uma obra de arte, que ela diz ter recebido como herança. Este projeto interativo on-line ${ }^{5}$, embora muito estruturado, uma vez que não dá opções de interatividade e autonomia para buscar respostas fora do ambiente, apresenta o desenvolvimento do trabalho de forma coerente e a informação pretendida pode ser sempre alcançada dentro do próprio

\footnotetext{
${ }^{3}$ Disponível em http://www.moma.org/ Acessado em 05/08/2003.

${ }^{4}$ Disponível em http://www.eduweb.com/portfolio/adventure.php. Acessado em 06/08/2003.

${ }^{5}$ Disponível em http://www.eduweb.com/pintura/ Acessado em 06/08/2003.
} 
ambiente através de múltiplas escolhas. Pode-se pensar que propostas deste âmbito sejam viáveis e produtivas como complemento de trabalhos de investigação em história da arte, alguns estilos de pintura. Seu caráter lúdico revela-se como uma possibilidade de uso na multimídia educativa.

Outro projeto dentro do site da Eduweb é o insideart ${ }^{6}$, ou como diz o nome, dentro da arte, ou arte vista de dentro. Este projeto interativo também possui um enfoque lúdico e conta a história de um menino que ao visitar um museu é "sugado" para dentro de uma obra. O roteiro revela a conversa dele com um peixe que supostamente estaria dentro do rio mostrado na obra de arte. Assim como o projeto anterior, este foi um dos primeiros projetos do site e ainda não apresenta uma estrutura aberta, e traz, inclusive, um questionário final para revisão de conteúdos. A riqueza do projeto consiste no acesso do educando a um mundo em que a imagem (da obra de arte) se torna parte da própria vida do sujeito da história. Como temos observado, este modelo de material multimídia para uso educacional apresenta lacunas na questão da autonomia do usuário, mas por outro lado viabiliza interação com imagens digitalizadas de obras as quais, muitas vezes, o educando não tem acesso no seu dia-a-dia, agregando um percurso possível de leitura destas imagens viabilizadas na web. É necessário que o professor tenha um conhecimento das características do meio tecnológico, e das possibilidades que este oferece uma vez que "acreditamos que o fato de trabalhar a partir de obras de arte disponibilizadas/viabilizadas neste ambiente, por si só não garante ao sujeito/educando a condição inventiva se aí não se instaurar um processo dialógico. Tal processo parece estabelecer-se com base em uma proposta pedagógica interativa que inclua situações com desafios favorecendo condições para decisões e escolhas, e estas, na medida em que viabilizarem mudanças internas, gerarem processos de criação" (Biazus, 2001).

The Joy of Visual Perception é um web site ${ }^{7}$ o qual seu autor, Peter Kayser, intitula web book. A data da autoria é 1996, quando experiências com frames, hipertexto e utilização de imagens (fixas e gifs animados) eram o grande avanço na utilização de materiais multimídia para uso educacional. Para este autor um web book difere dos livros tradicionais por consistir de figuras e diagramas suplementados por texto, o que não ocorre com a maioria dos livros tradicionais. Outro fator relevante apontado por Kayser é de que o web book aponta (links) para outras páginas da web. $\mathrm{O}$ autor menciona a autoria de um CD com as imagens do site, mas que estas estariam congeladas no tempo enquanto o conteúdo estaria sempre em atualização. Observa-se neste caso específico, que há uma marca de copyright do ano de 2003, o que sinaliza a não atualização em termos tecnológicos nesta quase uma década que nos separa da elaboração inicial do site, embora o autor declare que o web book estará em permanente atualização. Utilizamos este site nesta análise pelo grande número de imagens e diagramas disponibilizado, embora se constate que não é a imagem digital, nem o hipertexto com conteúdo consistente na área em questão, que garante a excelência das propostas em multimídia. Ao buscar sites que se apresentam como sendo de "livros online” encontramos muito material disponibilizado para leitura. Observa-se, porém, que o conceito de livro, com uma seqüência estruturada de capítulos e páginas seqüenciais permanece. Não há uma exploração do hipertexto, nem do acoplamento a outras mídias. A multimídia educacional para viabilizar o viver digital demanda interfaces em que a interação possa levar o educando a uma aprendizagem ativa, aonde o seu conteúdo vá

\footnotetext{
${ }^{6}$ Disponível em http://www.eduweb.com/insideart/ Acessado em 06/08/2003.

${ }^{7}$ Disponibilizado em: http://www.yorku.ca/eye/thejoy.htm. Acessado em 05/08/2003
} 
muito além daquele pré-determinado e congelado no CD que a instituição lhe oferece. A disponibilização de vários meios irá proporcionar ao educando diversidade nos caminhos a percorrer nos processos a construir.

Desse modo, uma questão que permanece presente na análise destes sites e projetos on-line e ainda merece estudos mais aprofundados é a relação entre a atualização tecnológica do material multimídia para uso em educação e os processos e resultados decorrentes desta.

Outro assunto a considerar no trabalho com a tecnologia em educação é a crescente utilização da imagem para definir paradigmas de navegação na comunicação em hipermídia. Search (2001) do Rensselaer Polytechnic Inst., USA, defende a idéia de que a arte eletrônica pode proporcionar novas perspectivas para o design de interfaces em hipermídia. Search considera importante a utilização dos programas de hipermídia para computadores nos processos educacionais, porém, sugere um olhar mais atento para a interface computacional que tem um papel fundamental na interpretação da informação quando da utilização destas. Os educandos são atraídos pela grande quantidade de informação disponibilizada, mas, freqüentemente, não sabem como organizar esta informação de modo a formar um todo coerente, e assim, desenvolver conceitos próprios dentro de uma perspectiva de autonomia. Os designs de interfaces que separam a informação em categorias fixas e estruturas hierárquicas não são favorecedores de meios que levem os usuários a sintetizar a informação, uma vez que o estabelecimento de relações entre estas partes não é priorizado.

Search encontra nos artistas eletrônicos o público que está desenvolvendo novas formas de discurso através de redes de associações na comunicação interativa eletrônica. Uma vez que os produtos para multimídia educacional estão ganhando aceitação pelos consumidores praticamente em todas as esferas das relações humanas, Trautwein e Werner (2002), do Center for Educational Research da Alemanha e da Universidade de Idaho, USA, respectivamente, analisaram alguns destes produtos e consideram que, muitos não são de boa qualidade e nem possuem uma base teórica densa ou mesmo dados empíricos que assegurem o seu valor para o uso educacional.

Em estudo desenvolvido com 64 sujeitos, Trautwein e Werner (2002), examinaram a eficácia da aplicação de multimídia no ensino da arte. Para tal estudo foram construídos 4 tipos diferentes de apresentações utilizando 12 imagens figurativas. Vários efeitos visuais tais como movimento, esfumados, aumento e dissolução das imagens, bem como textos falados foram usados para modificar os modos de compreensão dos observadores. As condições do experimento variavam em 2 aspectos: (a) a adequação dos efeitos visuais e (b) a apresentação adicional da informação verbal. Os achados confirmam a noção de que aplicações sofisticadas de multimídia ajudam o observador a desenvolver um modo de compreensão mais elaborado. A qualidade da experiência estética ou interesse estético dos observadores teve pouca influência nos resultados. Em contraste ao uso de multimídia sofisticada, o uso de elementos de multimídia (imagens e textos) com movimentos intermitentes não mostrou qualquer valor educativo. Este dado revela-se particularmente interessante, pois se observa que há algumas páginas da web, principalmente nos materiais para educação, com grande quantidade de elementos com movimento, o que foi provado não apresentar valor educativo.

Quando pensamos em material multimídia para educação, pensamos em elementos que envolvem apresentações - imagens e texto-, quer sejam para uso do professor ou do próprio educando ao desenvolver seu trabalho, portanto, é pertinente 
considerar dados que envolvam um usuário no que se refere à percepção de imagem e textos on-line. O uso da cor nos projetos multimídia tem sido pesquisado dentro do campo do $e$-business ${ }^{8}$ com vistas a melhor conhecer o seu público alvo.

As pesquisas da $3 \mathrm{M}$ na área comercial sobre o uso da cor ${ }^{9}$ mostram que a cor comunica mais eficientemente do que o uso do preto e branco. A questão sobre o grau de eficácia desta comunicação mostra que a cor é responsável por $60 \%$ da aceitação ou rejeição de um objeto e é fator crítico nas experiências visuais e que o uso da cor na propaganda vende mais do que as realizadas em preto e branco em $88 \%$.

A $3 \mathrm{M}$ foi mais além e realizou uma pesquisa com seus clientes de transparências para retroprojetor para conhecer as atitudes, crenças e percepções das pessoas que usam estas transparências para transmitir informações. Os resultados mostraram que 50\% acreditavam que a cor fazia o apresentador parecer mais profissional, $77 \%$ concordaram que apresentações que usam cores são capazes de comunicar melhor do que as feitas em preto e branco e $72 \%$ concordam que as apresentações que usam cores são lembradas por mais tempo do que as em preto e branco.

Portanto, ao pensar as questões relacionadas com os materiais multimídia para educação deve-se considerar tanto o sujeito usuário destes materiais, o educando, quanto o professor que irá propor / elaborar o design destes projetos e as suas crenças sobre estes materiais.

$\mathrm{O}$ e-business traz também dados estatísticos sobre os 10 maiores erros em sites voltados para $e$-business. Este estudo está disponibilizado no site USEIT ${ }^{10}$. Poderíamos, de maneira análoga, pensar quais as características que não devem estar presentes nos materiais multimídia disponibilizados para a educação. Por outro lado, a possibilidade de interatividade em um ambiente aberto, que viabilize a busca de caminhos com autonomia, deve estar no topo da lista das características que devem fazer parte de um ambiente multimídia para uso educacional.

\section{Novos desenvolvimentos em educação}

O grupo de pesquisa The Future of Learning Group do MIT ${ }^{11}$, USA, analisa as tecnologias na educação e como estas elicitam novos modos de pensar e aprender. Este grupo está desenvolvendo o projeto novas ferramentas com as quais pensar, que busca entender como esta tecnologia pode ajudar a realizar mudanças, proporcionando aprendizagens no mundo real das escolas, museus e comunidades menos privilegiada. $\mathrm{O}$ projeto guarda-chuva Aprendendo em um Mundo Digital, do qual o referido grupo faz parte, apresenta como hipóteses que: 1) o que se conhece sobre o que as crianças podem fazer em determinada faixa etária e de desenvolvimento está profundamente enraizado pelas condições do mundo pré-digital; 2) o modo como estas relações e estabelecem deve ser re-examinado; 3) o conteúdo e metodologias da "escola" necessitam uma revisão mais profunda do que o fizeram as reformas contemporâneas. Seymour Papert, que desenvolve esta linha de pesquisa, propõe repensar as teorias de desenvolvimento

\footnotetext{
${ }^{8}$ Comércio eletrônico

${ }^{9}$ Disponível em http://www.3m.com/meetingnetwork/readingroom/meetingguide power color.html. Acessado em 06/08/2003.

${ }_{11}^{10}$ Disponível em http://www.useit.com/alertbox/20021223.html/. Acessado em 06/08/2003.

${ }^{11} \mathrm{http}: / / \mathrm{www} \cdot \mathrm{mit} . \mathrm{edu} /$
} 
com relação ao que as pessoas e, especialmente crianças, deveriam aprender visando uma vida rica e produtiva na interação com o mundo digital.

A teoria da aprendizagem e educação, em desenvolvimento por Papert, construcionismo, está baseada na noção de que as pessoas aprendem ao ativamente construírem um novo conhecimento. Busca aprofundar a idéia de que as pessoas aprendem com eficiência quando estão engajadas construindo pessoalmente algo (um objeto, por exemplo) que tenha significado, que faça sentido. Este sentido só se constrói dentro de uma proposta dialógica, como propõe Bakhtin (2000) com vistas à autonomia do sujeito.

Alava (2002) ao definir as características que deve ter um curso multimídia para favorecer a autonomia na aprendizagem pontua que a utilização de produtos multimídia não garante a aprendizagem mais autônoma. As características dos meios utilizados para esta aprendizagem é que irão ter impacto sobre a autonomia do trabalho realizado pelos educandos. Stoney e Wild (1998) citados por Alava (2001) destacam o papel das interfaces enfatizando a interatividade e sugerem um "certo equilíbrio" entre o controle exercido pelo sistema e o que se permite ao aprendiz.

Nos projetos de Alava, as características que visam desenvolver autonomia nos educandos são: abertura para outros recursos materiais e humanos, utilização de modos de representação múltiplos, presença de atividades de favoreçam a aprendizagem, estabelecimento de uma rede de comunicação, acesso a ferramentas de pesquisa e de triagem de informação e acesso a ferramentas de acompanhamento do estudante na participação no desenvolvimento do processo.

A multimídia educacional demanda que haja abertura e flexibilidade através de interfaces que se adaptem ao usuário.

\section{Reflexões conclusivas}

É possível, então, viver o digital na multimídia utilizada com fins educacionais? $\mathrm{O}$ que implica viver este digital? Como se observa que este viver está ocorrendo nos trabalhos que temos analisado?

Pode-se, neste momento, falar sobre como a tecnologia a que temos acesso tem sido usada na área educacional, mesmo sabendo que a técnica não predispõe, mas determina novas condições. A técnica “... modela a percepção, age sobre o imaginário, impõe uma lógica figurativa, uma visão do mundo" (Couchot, 2003, p. 19). É necessário ainda considerar, mas não aprofundar esta questão aqui, a autonomia da técnica versus a autonomia do sujeito e analisar até que ponto há uma submissão de um ante o outro.

Há instituições que substituíram o livro por mídia eletrônica, por exemplo, o Boston College, USA, tornou obrigatório o uso de laptops por todos os seus estudantes, e criou livros texto multimídia em CD. Os livros eletrônicos foram desenvolvidos pelos professores (conteúdo) e produtores multimídia (parte técnica). As propriedades intelectuais foram preservadas pelos professores.

O que interessa saber num projeto desta envergadura é como se dá a relação professor / produtor de multimídia. Qual o lugar do educando? Há uma ótica em que o educando é inserido como tendo participação decisória no processo? Há maior preocupação com conteúdos do que processos educacionais? 
Observa-se que este viver digital está ocorrendo, em muitos casos, na esfera de tecnologia, mas o viver ao qual queremos nos referir possui um aspecto mais amplo e mostra um educando autônomo, imerso no ambiente digital fazendo escolhas sobre o meio que quer usar e pesquisando (utilizando estes meios) para elaborar o seu trabalho para que ocorram mudanças.

Viver o digital implica um mundo educativo em multimídia capaz de favorecer o trabalho partilhado em projetos colaborativos, que permitam ao educando o desenvolver dos processos de aprendizagem. As aprendizagens - transformadora -, no enfoque de (Jack Mezirow, 1990, 1991) citado em Palloff e Pratt (2002), por ter base na reflexão e na interpretação de experiências, idéias e proposições já adquiridas, ou através da construção, como propõe Papert com a noção de construcionismo, apontam para propostas educacionais viabilizadas nos ambientes tecnológicos. Propostas centradas em conteúdos, centradas no professor, não servem mais nos novos cenários disponibilizados pelas mídias digitais. No entanto, muitos projetos para uso em multimídia educacional trazem ainda o viés de antigas idéias e conceitos sobre educação sob uma nova roupagem tecnológica.

É possível viver o digital na multimídia utilizada com fins educacionais desde que as propostas pedagógicas apresentadas aos educandos tenham as condições que abordamos neste texto, e que o professor não seja um mero utilizador de novas tecnologias proporcionadas por suas instituições, mas que compreenda o que é o mundo na era da informação digital, um mundo em que é possível criar e recriar através da simulação.

Esta criação, e re-criação, que implica trabalhar com as realidades, o que tende a levar a um viver digital produtivo pode ocorrer tanto através do trabalho com a imagem digital quanto do trabalho com outras propostas no meio digital. A imagem é para Couchot (2003) “... um análogo purificado e transmutado pelo cálculo. Análogo numérico do mundo, das coisas - das realidades naturais ou artificiais...".

Assim como a imagem pode ser vista como um análogo numérico de mundo, as propostas na área da multimídia em educação deverão estar inculcadas no, e pelo, meio/contexto do educando. 


\section{Referências Bibliográficas}

1. Alava, S.(org.). Ciberespaço e formações abertas: rumo a novas práticas educacionais? Porto Alegre : Artmed, 2002.

2. Bakhtin, Mikhail. Estética da criação verbal. São Paulo: Martins Fontes, 2000

3. Biazus, Maria Cristina V. Ambientes digitais e processos de criação : gerando a produção de sentido. Tese (doutorado) - Universidade Federal do Rio Grande do Sul. Programa de Pós-Graduação em Informática na Educação. Porto Alegre : UFRGS, 2001.

4. Couchot, E. A tecnologia na arte: da fotografia à realidade virtual. Porto Alegre: Editora da UFRGS, 2003.

5. Palloff, R. e Pratt, K. Construindo comunidades de aprendizagem no ciberespaço. Porto Alegre : Artmed, 2002.

6. Search, P. Using Electronic Art to Define Navigation Paradigms for Hypermedia Communication. World Conference on Educational Multimedia, Hypermedia and Telecommunications 2001 (1), 1673-1678. Disponível em: http://dl.aace.org/8844 . Acessado em 02/08/2003.

7. Werner, S. Old Paintings, New Technology: Does Instructive Animation Make Sense in Art Education?. Journal of Educational Multimedia and Hypermedia 10(3), 253-272. Disponível em: http://dl.aace.org/6497. Acessado em 02/08/2003. 